evidence of damage below low tide. The impression of the present writer, however, for what it is worth, is that in a limited area where pollution may be high, animals not exposed between tide-marks suffer and may be exterminated, and the supposition was that even if adult sessile forms may be able to withstand pollution, the delicate free-swimming ciliated larvæ, by which most sessile forms propagate, succumbed, and multiplication accordingly ceased. But that and several other matters referred to in the report await the test of experiment.

\section{Economic Value of an Experiment in Transplanting}

For some seventy years before 1917, the State of Pennsylvania possessed no beavers, and in that year two, imported from Wisconsin, were set free. Between 1917 and $-1924,94$ beavers were imported and liberated at a cost of about 50 dollars each. So rapidly did the creatures multiply that it soon became necessary to transfer some to other parts of the State.' A survey by the Board of Game Commissioners gives an idea of what the increase meant: in 1931 there were 899 beaver dams with an estimated population of 4,377 ; in 1934 , the population had risen to 15,000 . During the trapping season of 1934 the number of beavers taken was 6,455 , and the pelts brought the trappers a sum total of 22,610 dollars. Wherever beavers are doing damage, as in farming communities or in irrigation areas, the policy of the U.S. Bureau of Biological Survey has been to encourage and aid in the transference of the animals to carefully selected sites where their dam building may aid in the cause of conservation. To further this policy, the Bureau has published a Farmers Bulletin (No. 1768) on "Trapping and Transplanting Live Beavers", in which live-beaver traps are described and trapping methods and transport are discussed for the help of farmers, stockmen, foresters and others interested in beaver control.

\section{An Air-Conditioning Unit}

AN air-conditioning unit is usually a small cabinet, the only external evidence of its purpose being two small grilles. In Engineering of July 9, a description is given of one meant to stand on the room floor and placed near a window as the air inlet can then be readily arranged. It is about $40 \mathrm{in}$. high, $30 \mathrm{in}$. wide and $18 \mathrm{in}$. deep. It is electrically operated, and the supply cable can be plugged into any existing power point such as one used for a radio cabinet. With the air-cooled type this is all that is required, but with the water-cooled type connexions are needed with the water supply. In both summer and winter, the incoming air is first filtered; the inlet is a permanent fixture and does not interfere with opening the window for eleaning. Otherwise the window is kept closed to keep out the noise of street traffic. The fan is driven by a motor independent of the fans used for cooling and so can provide ventilation without either heating or cooling, if the outside air is in the desired condition. The cooling of the air and the removal of excess moisture by condensation is effected by a special refrigerator. The condensate is then re-evaporated and carried outside, so no drainpipe is required in the air-cooled unit. For increasing the moisture in the air, the water in the humidifier tank is vaporized by an electric immersion heater. The relative humidity is settled by a hygrostat which automatically controls the heater. A small neon light indicates when the heating elements are working, and reminds the occupant to consider whether it is advisable to turn off the heat at night when leaving the conditioning plant running.

\section{Atmospheric Pollution}

THE twenty-second report on atmospheric pollution contains an account of observations for the year ending March 31, 1936 (London : H.M. Stationery Office, 1937. 6s. net). Reviewing the last twenty years, it is concluded that the effort and propaganda of the period have brought about an appreciable reduction in air contamination. This now seems to have ceased, or even changed to a slight rise, probably on account of the increased industrial activity. Again the figures for some London stations are very high, especially for sulphur. Westminster shows some of the highest figures, and compares very unfavourably with some of the industrial areas. In some cases, remarkable improvements have been rendered over a period of years, and the causes deserve scrutiny. The report is cautious in its interpretation, as the difficulty of sampling is obvious. At Burnley a fifty per cent fall has been recorded in ten years - attributed to the removal of a factory. Attention is directed to the high drop at Wakefield in total deposit, from 613 tons per square mile in 1924 to 227 tons in 1935 . This may be associated with the persistent efforts made by the authorities there, and shows what is possible when those who wield political power treat seriously the problem of cleaner air. Unfortunately, it is only too rare that in local authorities the will and wish to improve the atmosphere are combined. The most important development recorded is the initiation of an intensive survey in and around Leicester-selected because it is relatively isolated from other industrial areas likely to prove disturbing factors.

\section{Empire Conference on Tuberculosis}

ThE Minister of Health, Sir Kingsley Wood, delivered the inaugural address on May 3 at the Empire Conference on the "Care and After-care of the Tuberculous" at Overseas House, St. James's, London. $\mathrm{He}$ first reviewed tuberculosis as a cause of mortality in England and Wales. The standardized death-rate from this disease has fallen from 3,638 per million of population in 1851-55 to 687 in 1935; nevertheless, tuberculosis in this country still comes next to cancer in the list of killing diseases. Sir Kingsley next dealt with the public provision for the treatment of tuberculosis - 29,000 beds in approved institutions -and the amount of expenditure thereon. $\mathrm{He}$ commended particularly the value of village settlements for treatment and after-care, and emphasized the importance of the after-care of patients who did not enter a village settlement. 